\title{
Obstetric Outcomes in Women in Fukushima Prefecture during and after the Great East Japan Earthquake and Fukushima Nuclear Power Plant Accident: The Fukushima Health Management Survey
}

\author{
Masako Hayashi1,2, Keiya Fujimori1,3, Seiji Yasumura1,4, Aya Goto',4, Akihito Nakai1,2 \\ ${ }^{1}$ Radiation Medical Science Center for the Fukushima Health Management Survey, Fukushima, Japan \\ ${ }^{2}$ Department of Obstetrics and Gynecology, Nippon Medical School, Tama Nagayama Hospital, Tokyo, Japan \\ ${ }^{3}$ Department of Obstetrics and Gynecology, School of Medicine, Fukushima Medical University, Fukushima, Japan \\ ${ }^{4}$ Department of Public Health, School of Medicine, Fukushima Medical University, Fukushima, Japan \\ Email: hayashi@nms.ac.jp
}

How to cite this paper: Hayashi, M., Fujimori, K., Yasumura, S., Goto, A. and Nakai, A. (2016) Obstetric Outcomes in Women in Fukushima Prefecture during and after the Great East Japan Earthquake and Fukushima Nuclear Power Plant Accident: The Fukushima Health Management Survey. Open Journal of Obstetrics and Gynecology, 6, 705-713.

http://dx.doi.org/10.4236/ojog.2016.612088

Received: October 11, 2016

Accepted: November 8, 2016

Published: November 11, 2016

Copyright $\odot 2016$ by authors and Scientific Research Publishing Inc. This work is licensed under the Creative Commons Attribution International License (CC BY 4.0).

http://creativecommons.org/licenses/by/4.0/

\section{(c) (i) Open Access}

\begin{abstract}
Objective: The Great East Japan Earthquake (magnitude, 9.0) followed by a largescale tsunami caused a severe nuclear accident at the Fukushima Daiichi Nuclear Power Plant (Tokyo Electric Company). This study aimed to evaluate the obstetric outcomes in women in Fukushima prefecture during and after the Great East Japan Earthquake and Fukushima nuclear power plant accident. Methods: We collected information for 12,300 pregnant women who conceived during the 9 months before and after the disaster in Fukushima prefecture. The data of the subjects were analyzed according to the conception date for each pregnancy. Results: Among the women who conceived within 9 months before the disaster, adverse obstetric outcomes were not observed. In contrast, in the case of women who conceived within 6 months after the disaster, an increase in the incidence of preterm birth (less than 37 weeks) and low birth weight (less than $1500 \mathrm{~g}$ and less than $2500 \mathrm{~g}$ ) was observed. Moreover, these women showed an increased incidence of medical complications, such as respiratory diseases and mental disorders. Conclusion: The results of the present study show that the occurrence of adverse obstetric outcomes was higher in the women who conceived within 6 months after the disaster than in those who were pregnant at the time of the disaster. The results may be related to emotional stress such as anxiety about the disaster and emphasize the need for continued investigations and careful management of pregnant woman in disaster areas in the future.
\end{abstract}




\section{Keywords}

Earthquake, Nuclear Accident, Pregnancy, Preterm Birth, Low Birth Weight

\section{Introduction}

On March 11, 2011, the Great East Japan Earthquake (magnitude, 9.0) followed by a large-scale tsunami more than $16.0 \mathrm{~m}$ high led to a humanitarian and material disaster in northeastern Japan. The earthquake and tsunami also caused a severe nuclear accident at the Fukushima Daiichi Nuclear Power Plant (Tokyo Electric Company) located in east-central Fukushima prefecture, approximately $180 \mathrm{~km}$ southwest of the earthquake hypocenter.

Immediately after the disaster, Fukushima prefectural government performed the Fukushima Health Management Survey to support long-term health management of the residents and to investigate low-dose radiation exposure caused by the accident [1]. A pregnancy and birth survey was included in this survey to improve obstetrical and prenatal care and to support women who were pregnant or delivered babies in Fukushima prefecture during and after the disaster [2].

Several reports have indicated that disasters such as earthquakes [3]-[7] and nuclear reactor accidents [8]-[15] influence various aspects of perinatal health. In addition, pregnant women with posttraumatic stress disorders have been reported to be at an increased risk for adverse perinatal outcomes [16]-[18]. Our previous study showed that the incidence of adverse obstetric outcomes immediately before and after the Great East Japan Earthquake did not remarkably differ between pregnant women living in Fukushima prefecture and the general population in Japan [2]. The obstetric outcomes in women who conceived after the disaster, however, remain unclear.

In the present study, we extended the observation period of our previous study and assessed the obstetric outcomes in women who conceived before and after the disaster to evaluate the effect of the Great East Japan Earthquake and Fukushima nuclear power plant accident in Fukushima prefecture. We used the data from the pregnancy and birth survey performed by the Radiation Medical Science Center; this survey was one of the detailed surveys included in the Fukushima Health Management Survey. The survey questionnaires allowed us to differentiate among the conception dates of all the pregnancies and to compare the obstetric outcomes between women who conceived before and those who conceived after the disaster.

\section{Material and Methods}

The pregnancy and birth survey was conducted among women who received maternal and child health handbooks from municipal officers in Fukushima prefecture between August 1, 2010 and July 31, 2012, and among women who received handbooks from municipal officers in other prefectures but who received prenatal care or delivered babies in Fukushima prefecture after the disaster. This survey was approved by the ethics 
committee of Fukushima Medical University, which is regulated by local policy, national law, and the World Medical Association Declaration of Helsinki. The written informed consent to participate in this study is included in returned completed questionnaires.

The questionnaires, which can be accessed on our website [1], were mailed since January 18, 2012. In total, 30,517 questionnaires were distributed. The number of responses as on March 31, 2014 was 16,401 (53.7\% response rate).

The questionnaire included information on maternal and infant characteristics, such as maternal age, history of infertility treatments, medical complications, pregnancy complications, expected date of confinement, gestational age at delivery, birth weight, delivery mode, and major congenital anomalies. These data conform to uniform coding specifications; further, the data have passed a rigorous quality check and have been edited and reviewed by the Radiation Medical Science Center.

Data for 16,123 respondents were included in the analysis after exclusion of 278 invalid responses. To evaluate the obstetric outcomes in women in Fukushima prefecture during and after the Great East Japan Earthquake and Fukushima nuclear power plant accident, we estimated the conception date of each pregnancy from the gestational age at delivery or expected date of confinement. On the basis of the conception date, we used data of 12,300 women who conceived during the 9 months before and after the disaster (from June 11, 2010 to December 10, 2011).

Women who conceived within 9 months before the disaster were categorized every 3 months depending on the conception date ( 9 - 7 months before the disaster: from June 11 to September 10, 2010; 6 - 4 months before the disaster: from September 11 to December 10, 2010; and 3 - 0 months before the disaster: December 11, 2010 to March 10, 2011). Two hundred seventeen women in the 9 - 7 months before the disaster, 12 women in the 6 - 4 months before the disaster, and 4 women in the 3 - 0 months before the disaster underwent spontaneous abortion or delivered before March 11, 2011. For the accurate calculation of the incidence of obstetric complications, such as preterm birth rate and low-birth-weight rate, the data of these women who underwent spontaneous abortion or delivered before March 11, 2011 were included in the analysis. The remaining participants who conceived within 9 months after the disaster were also classified every 3 months according to the conception date ( 0 - 3 months: from March 11 to June 10, 2011; 4 - 6 months: from June 11 to September 10, 2011; and 7 - 9 months: from September 11 to December 10, 2011), and their data were assessed.

Data were analyzed using SPSS Statistics for Windows, version 17.0 (SPSS Inc., Chicago, IL, USA) and Excel (Microsoft, Redmond, WA, USA). Statistical analysis of continuous variables, such as maternal age and birth weight, was performed using ANOVA followed by Scheffé's test; categorical variables were analyzed using the chi-squared test followed by Bonferroni correction. p values less than 0.05 were considered statistically significant.

\section{Results}

In total, 7053 women $(9-7$ month, $\mathrm{n}=2097 ; 6-4$ month, $\mathrm{n}=2528 ; 3-0$ month, $\mathrm{n}=$ 
2428) and 5247 women ( 0 - 3 months, $\mathrm{n}=1728 ; 4-6$ months, $\mathrm{n}=1647 ; 7$ - 9 months, $\mathrm{n}=1872$ ) conceived during the 9 months before and during the 9 months after the Great East Japan Earthquake and Fukushima nuclear power plant accident, respectively.

The maternal characteristics of the study groups are summarized in Table 1 . Among women who conceived within 9 months before the disaster, no significant differences were observed in their characteristics, regardless of the study periods. Among women who conceived within 3 months after the disaster, decreases in the maternal age and the proportion of in vitro fertilization (IVF-ET) were observed. Among women who conceived between 4 and 6 months after the disaster, a significant increase in the incidence of respiratory diseases and a slight increase in mental disorders, were observed. Among

Table 1. Maternal characteristics of respondents.

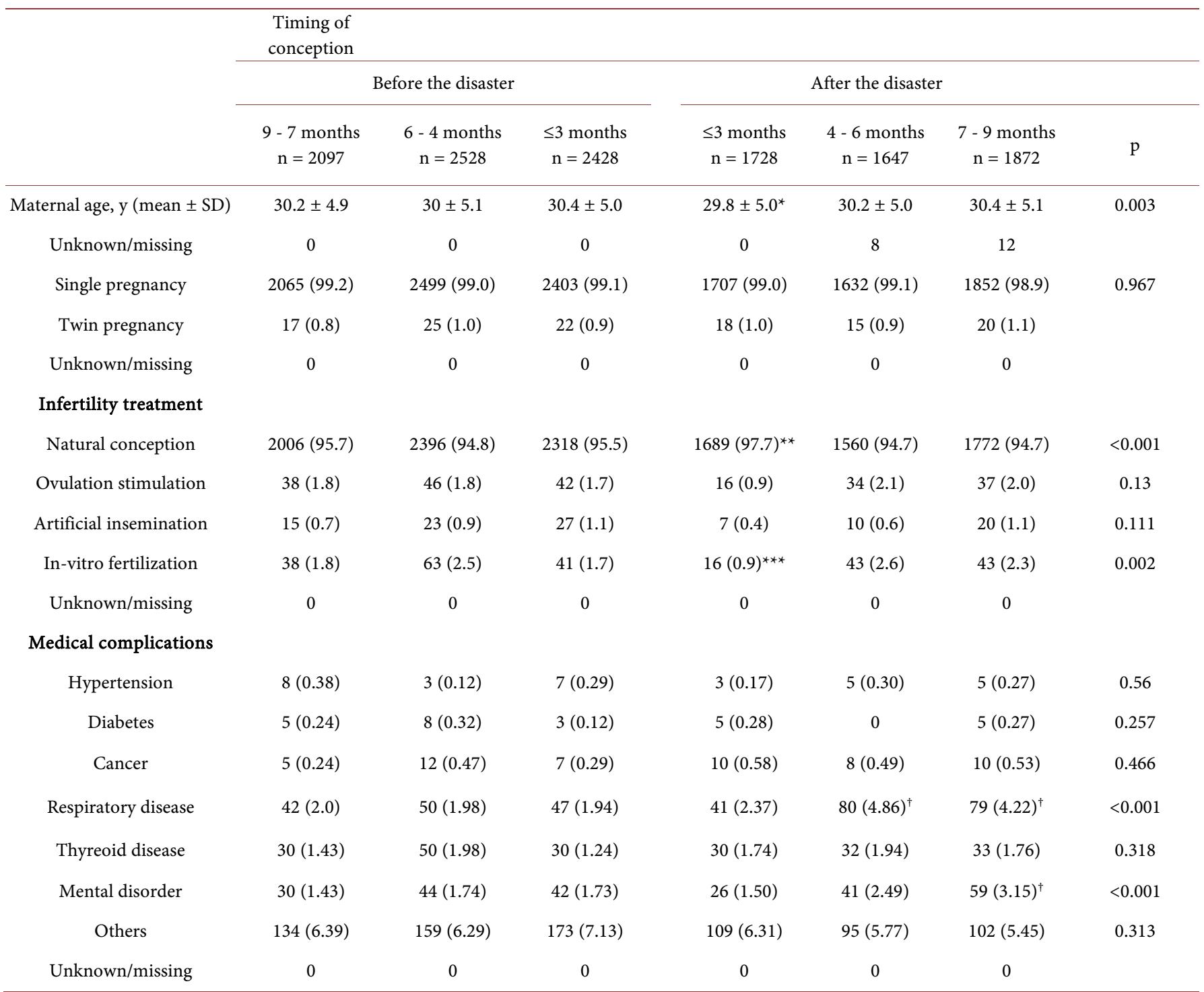

Number in parentheses are the percentage. ${ }^{*} \mathrm{p}<0.05$, in relation to the $\leq 3$ months before the disaster group. ${ }^{* *} \mathrm{p}<0.05$, in relation to all other groups. ${ }^{* *} \mathrm{p}<0.05$, in relation to the 6 - 4 months before the disaster group, 4 - 6 months after the disaster group, and 7 - 9 after the disaster group. ${ }^{\dagger}$ p $<0.05$, in relation to the before the disaster groups, and $\leq 3$ months after the disaster group. 
women who conceived between 7 and 9 months after the disaster, a significant increase in the incidence of the medical complications, such as respiratory diseases and mental disorders, was observed. The obstetric outcomes in the study groups are summarized in Table 2. Women who conceived within 9 months before the disaster showed no significant increases in the incidences of cesarean section, preterm birth, and low birth weight, regardless of the study periods. In contrast, among women who conceived within 6 months after the disaster, a significant decrease in the birth weight was observed; moreover, a decrease in the neonatal body weight at 1 month of age was observed in the case of these women. Of these, among the women who conceived within 3 month after the disaster, an increase in the incidence of low birth weight (less than 1500 $\mathrm{g}$ and less than $2500 \mathrm{~g}$ ) was observed. A slight and a significant increase in the incidence of preterm birth (less than 37 weeks) were also observed among the women who

Table 2. Obstetric outcomes of respondents.

\begin{tabular}{|c|c|c|c|c|c|c|c|}
\hline & \multicolumn{6}{|c|}{ Timing of conception } & \multirow[b]{3}{*}{$\mathrm{p}$} \\
\hline & \multicolumn{3}{|c|}{ Before the disaster } & \multicolumn{3}{|c|}{ After the disaster } & \\
\hline & $\begin{array}{c}9-7 \text { months } \\
\mathrm{n}=2097\end{array}$ & $\begin{array}{c}6-4 \text { months } \\
\mathrm{n}=2528\end{array}$ & $\begin{array}{c}\leq 3 \text { months } \\
\mathrm{n}=2428\end{array}$ & $\begin{array}{l}\leq 3 \text { months } \\
\mathrm{n}=1728\end{array}$ & $\begin{array}{c}4 \text { - } 6 \text { months } \\
\mathrm{n}=1647\end{array}$ & $\begin{array}{c}7 \text { - } 9 \text { months } \\
\mathrm{n}=1872\end{array}$ & \\
\hline $\begin{array}{l}\text { The number of delivery and abortion before the } \\
\text { disaster }\end{array}$ & 217 & 12 & 4 & 0 & 0 & 0 & \\
\hline \multicolumn{8}{|l|}{ Delivery mode } \\
\hline Spontaneous cephalic & $1421(69.6)$ & $1692(68.3)$ & $1628(68.7)$ & $1153(68.5)$ & $1052(67.4)$ & $1190(66.9)$ & 0.579 \\
\hline Instrumental & $205(10.0)$ & $245(9.9)$ & $273(11.5)$ & $165(9.8)$ & $179(11.5)$ & $212(11.9)$ & 0.094 \\
\hline Cesarean & $417(20.4)$ & $540(21.8)$ & $470(19.8)$ & $365(21.7)$ & $330(21.1)$ & $376(21.1)$ & 0.566 \\
\hline Unknown/missing & 54 & 51 & 57 & 45 & 86 & 94 & \\
\hline \multicolumn{8}{|l|}{ Preterm birth } \\
\hline$<28$ weeks & $2(0.10)$ & $8(0.32)$ & $5(0.21)$ & $8(0.47)$ & $5(0.31)$ & $6(0.32)$ & 0.364 \\
\hline$<34$ weeks & $13(0.62)$ & $30(1.19)$ & $23(0.96)$ & $26(1.52)$ & $23(1.41)$ & $17(0.91)$ & 0.078 \\
\hline$<37$ weeks & $90(4.30)$ & $119(4.73)$ & $99(4.13)$ & $94(5.48)$ & $105(6.42)^{*}$ & $86(4.63)$ & 0.013 \\
\hline Unknown/missing & 0 & 0 & 0 & 0 & 0 & 0 & \\
\hline Infants & $\mathrm{n}=2108$ & $\mathrm{n}=2539$ & $\mathrm{n}=2417$ & $\mathrm{n}=1731$ & $\mathrm{n}=1650$ & $\mathrm{n}=1877$ & $\mathrm{p}$ \\
\hline The number of the birth before the disaster & 214 & 0 & 0 & 0 & 0 & 0 & \\
\hline Birthweight $(\mathrm{g} \pm \mathrm{SD})$ & $3008 \pm 396$ & $3012 \pm 428$ & $3028 \pm 415$ & $2978 \pm 448^{*}$ & $2982 \pm 438^{*}$ & $2997 \pm 433$ & 0.001 \\
\hline$<1000 \mathrm{~g}$ & $1(0.05)$ & $9(0.36)$ & $5(0.21)$ & $8(0.47)$ & $7(0.43)$ & $7(0.38)$ & 0.148 \\
\hline$<1500 \mathrm{~g}$ & $7(0.34)$ & $16(0.64)$ & $11(0.46)$ & $20(1.16)^{* *}$ & $15(0.92)$ & $11(0.59)$ & 0.02 \\
\hline$<2500 \mathrm{~g}$ & $185(8.87)$ & $229(9.1)$ & $187(7.78)$ & $185(10.76)^{*}$ & $160(9.82)$ & $175(9.42)$ & 0.036 \\
\hline Unknown/missing & 23 & 22 & 14 & 11 & 20 & 19 & \\
\hline Congenital anomalies & $52(2.56)$ & $60(2.45)$ & $73(3.16)$ & $46(2.75)$ & $42(2.6)$ & $45(2.46)$ & 0.693 \\
\hline Unknown/missing & 74 & 95 & 105 & 57 & 33 & 45 & \\
\hline Bodyweight at a month old $(\mathrm{g} \pm \mathrm{SD})$ & $4224 \pm 574$ & $4243 \pm 598$ & $4226 \pm 572$ & $4128 \pm 602^{\dagger}$ & $4176 \pm 594^{\ddagger}$ & $4225 \pm 603$ & $<0.001$ \\
\hline Unknown/missing & 24 & 24 & 24 & 122 & 22 & 22 & \\
\hline
\end{tabular}

Number in parentheses are the percentage. ${ }^{\star} \mathrm{p}<0.05$, in relation to $\leq 3$ months before the disaster group. ${ }^{*} \mathrm{p}<0.05$, in relation to $9-7$ months before the disaster group. ${ }^{\dagger} \mathrm{p}<0.05$, in relation to the before the disaster groups and $9-7$ monthes after the disaster group. ${ }^{*} \mathrm{p}<0.05$, in relation to the $6-4$ months before the disaster group. 
conceived between 4 and 6 months after the disaster, respectively.

\section{Discussion}

The results of the present study showed that adverse obstetric outcomes occurred in women who conceived within 6 months after the disaster rather than in women who were pregnant at the time of the disaster.

Although disasters such as earthquakes [3]-[7] and nuclear reactor accidents [8]-[15] may influence various aspects of perinatal health, their influence on perinatal outcomes varies according to the disaster scale and area. Many birth complications, including low birth weight, preterm birth, birth defects, and lower Apgar scores, were reported after the Chinese Wenchuan earthquake in 2008, which caused nearly 70,000 deaths because of its severity [3]. The Taiwan earthquake in 1999 was associated with low birth weight and minor psychiatric morbidity [4]. Increases in the incidence of preterm birth were also reported after the Northridge earthquake California in 1994 [5] and the Israel earthquakes in 1985 [6]. Nuclear reactor accidents such as the Chernobyl nuclear disaster in Ukraine in 1986 and the Three Mile Island disaster in Pennsylvania in 1979 also affected perinatal outcomes. Increased rates of Down syndrome and neural tube defects were reported after the Chernobyl nuclear disaster [9] [11], although data from the most affected areas are limited [8]. In contrast, the Three Mile Island disaster was associated with increased depression and anxiety immediately after the disaster [13], but it did not have any effect on the physical functions, such as spontaneous abortion [12].

Our previous study showed that the incidence of adverse obstetric outcomes immediately before and after the disaster did not remarkably differ between pregnant women living in Fukushima prefecture and the general population in Japan [2]. In the previous study, the incidence of complications, such as stillbirth, preterm birth, and congenital anomalies, was not related to the distance from the Fukushima nuclear power plant and the earthquake hypocenter [2]. In concordant with our previous data, the present data of women who conceived within 9 months before the disaster showed no adverse obstetric outcomes. Taken together, the previous results and the current results suggest that the influence of the Great East Japan Earthquake and Fukushima nuclear power plant accident on perinatal outcomes in Fukushima prefecture was limited as compared to the influence of the Chinese Wenchuan earthquake or the Chernobyl nuclear disaster on perinatal outcomes.

However, the present study, in which the observation period of the previous study was extended, showed that the incidence of adverse outcomes might increase after the disaster. Women who conceived after the disaster were more likely to develop respiratory diseases, mental disorders, preterm birth, and low birth weight infant than those before the disaster. One possible explanation is that even though a direct exposure to the disaster was absent, the surrounding environment may lead to the adverse perinatal outcomes. In fact, pregnant women with posttraumatic stress disorders have been reported to be at an increased risk of adverse perinatal outcomes [16]-[18]. A previous study showed that anxiety due to the Chernobyl disaster, but not the environmental 
threat itself, was associated with preterm births in a sample of Swedish women [19]. In addition, previous studies demonstrated an increase in the respiratory diseases, such as chronic obstructive pulmonary disease and asthma, after the disasters including the Great East Japan Earthquake [20]-[26], in concordant with our results on maternal complications. In these reports, several authors suggested that the increase is significantly related to emotional stress such as anxiety about the disaster [21] [26]. Therefore, women who conceived after the disaster might experience uneasiness despite the absence of a direct exposure to the disaster. This raises the possibility that the surrounding environment after the disaster might lead to the adverse obstetric outcomes.

The findings should be interpreted with caution, because the survey questionnaires included various biases, such as self-selection bias, because the response rate of questionnaire (53.7\%) might be not necessarily high, and because the influence of the disaster varies according to the area and passage of time. In addition, because the survey did not use data from the medical records of the hospitals, the possibility that some participants gave birth outside Fukushima prefecture cannot be excluded. However, our results, which showed that the incidence of the adverse outcomes might increase after the disaster, emphasize the need for continued investigation and careful management for pregnant woman in disaster-affected areas.

\section{Acknowledgements}

This survey was supported by the national "Health Fund for Children and Adults Affected by the Nuclear Incident". The findings and conclusions of this study are solely the responsibility of the authors and do not represent the official views of Fukushima prefecture government.

\section{References}

[1] Yasumura, S., Hosoya, M., Yamashita, S., Kamiya, K., Abe, M., Akashi, M., et al. (2012) Study Protocol for the Fukushima Health Management Survey. Journal of Epidemiology/ Japan Epidemiological Association, 22, 375-383. http://dx.doi.org/10.2188/jea.JE20120105

[2] Fujimori, K., Kyozuka, H., Yasuda, S., Goto, A., Yasumura, S., Ota, M., et al. (2014) Pregnancy and Birth Survey after the Great East Japan Earthquake and Fukushima Daiichi Nuclear Power Plant Accident in Fukushima Prefecture. Fukushima Journal of Medical Science, 60, 75-81. http://dx.doi.org/10.5387/fms.2014-9

[3] Tan, C.E., Li, H.J., Zhang, X.G., Zhang, H., Han, P.Y., An, Q., et al. (2009) The Impact of the Wenchuan Earthquake on Birth Outcomes. PloS ONE, 4, e8200. http://dx.doi.org/10.1371/journal.pone.0008200

[4] Chang, H.L., Chang, T.C., Lin, T.Y. and Kuo, S.S. (2002) Psychiatric Morbidity and Pregnancy Outcome in a Disaster Area of Taiwan 921 Earthquake. Psychiatry and Clinical Neurosciences, 56, 139-144. http://dx.doi.org/10.1046/j.1440-1819.2002.00948.x

[5] Glynn, L.M., Wadhwa, P.D., Dunkel-Schetter, C., Chicz-Demet, A. and Sandman, C.A. (2001) When Stress Happens Matters: Effects of Earthquake Timing on Stress Responsivity in Pregnancy. American Journal of Obstetrics and Gynecology, 184, 637-642. http://dx.doi.org/10.1067/mob.2001.111066 
[6] Weissman, A., Siegler, E., Neiger, R., Jakobi, P. and Zimmer, E.Z. (1989) The Influence of Increased Seismic Activity on Pregnancy Outcome. European Journal of Obstetrics, Gynecology, and Reproductive Biology, 31, 233-236.

http://dx.doi.org/10.1016/0028-2243(89)90158-5

[7] Harville, E., Xiong, X. and Buekens, P. (2010) Disasters and Perinatal Health: A Systematic Review. Obstetrical \& Gynecological Survey, 65, 713-728.

http://dx.doi.org/10.1097/OGX.0b013e31820eddbe

[8] Little, J. (1993) The Chernobyl Accident, Congenital Anomalies and Other Reproductive Outcomes. Paediatric and Perinatal Epidemiology, 7, 121-151. http://dx.doi.org/10.1111/j.1365-3016.1993.tb00388.x

[9] Hoffmann, W. (2001) Fallout from the Chernobyl Nuclear Disaster and Congenital Malformations in Europe. Archives of Environmental Health, 56, 478-484. http://dx.doi.org/10.1080/00039890109602895

[10] Dolk, H. and Nichols, R. (1999) Evaluation of the Impact of Chernobyl on the Prevalence of Congenital Anomalies in 16 Regions of Europe. EUROCAT Working Group. International Journal of Epidemiology, 28, 941-948. http://dx.doi.org/10.1093/ije/28.5.941

[11] Zafra Anta, M.A., Amor Cabrera, M.A., Diaz Mier, F. and Camara Morano, C. (2002) [Health Effects of the Chernobyl Disaster. Fifteen Years Afterwards]. Analesespanoles de pediatria, 56, 324-333. http://dx.doi.org/10.1016/S1695-4033(02)77810-7

[12] Goldhaber, M.K., Staub, S.L. and Tokuhata, G.K. (1983) Spontaneous Abortions after the Three Mile Island Nuclear Accident: A Life Table Analysis. American Journal of Public Health, 73, 752-759. http://dx.doi.org/10.2105/AJPH.73.7.752

[13] Houts, P.S., Tokuhata, G.K., Bratz, J., Bartholomew, M.J. and Sheffer, K.W. (1991) Effect of Pregnancy during TMI Crisis on Mothers' Mental Health and Their Child's Development. American Journal of Public Health, 81, 384-386. http://dx.doi.org/10.2105/AJPH.81.3.384

[14] Wertelecki, W. (2010) Malformations in a Chornobyl-Impacted Region. Pediatrics, 125, e836-e843. http://dx.doi.org/10.1542/peds.2009-2219

[15] Feshchenko, S.P., Schroder, H.C., Muller, W.E. and Lazjuk, G.I. (2002) Congenital Malformations among Newborns and Developmental Abnormalities among Human Embryos in Belarus after Chernobyl Accident. Cellular and Molecular Biology, 48, 423-426.

[16] Rogal, S.S., Poschman, K., Belanger, K., Howell, H.B., Smith, M.V., Medina, J., et al. (2007) Effects of Posttraumatic Stress Disorder on Pregnancy Outcomes. Journal of Affective Disorders, 102, 137-143. http://dx.doi.org/10.1016/j.jad.2007.01.003

[17] Shaw, J.G., Asch, S.M., Kimerling, R., Frayne, S.M., Shaw, K.A. and Phibbs, C.S. (2014) Posttraumatic Stress Disorder and Risk of Spontaneous Preterm Birth. Obstetrics and Gynecology, 124, 1111-1119. http://dx.doi.org/10.1097/AOG.0000000000000542

[18] Morland, L., Goebert, D., Onoye, J., Frattarelli, L., Derauf, C., Herbst, M., et al. (2007) Posttraumatic Stress Disorder and Pregnancy Health: Preliminary Update and Implications. Psychosomatics, 48, 304-308. http://dx.doi.org/10.1176/appi.psy.48.4.304

[19] Levi, R., Lundberg, U. and Hanson, U. (1989) Anxiety during Pregnancy after the Chernobyl Accident as Related to Obstetric Outcome. Journal of Psychosomatic Obstetrics \& Gynecology, 10, 221-230. http://dx.doi.org/10.3109/01674828909016696

[20] Takakura, R., Himeno, S., Kanayama, Y., Sonoda, T., Kiriyama, K., Furubayashi, T., et al. (1997) Follow-Up after the Hanshin-Awaji Earthquake: Diverse Influences on Pneumonia, Bronchial Asthma, Peptic Ulcer and Diabetes Mellitus. Internal Medicine, 36, 87-91. http://dx.doi.org/10.2169/internalmedicine.36.87

[21] Fagan, J., Galea, S., Ahern, J., Bonner, S. and Vlahov, D. (2003) Relationship of Self- 
Reported Asthma Severity and Urgent Health Care Utilization to Psychological Sequelae of the September 11, 2001 Terrorist Attacks on the World Trade Center among New York City Area Residents. Psychosomatic Medicine, 65, 993-996. http://dx.doi.org/10.1097/01.PSY.0000097334.48556.5F

[22] Chierakul, W., Winothai, W., Wattanawaitunechai, C., Wuthiekanun, V., Rugtaengan, T., Rattanalertnavee, J., et al. (2005) Melioidosis in 6 Tsunami Survivors in Southern Thailand. Clinical Infectious Diseases, 41, 982-990. http://dx.doi.org/10.1086/432942

[23] Ohkouchi, S., Shibuya, R., Yanai, M., Kikuchi, Y., Ichinose, M. and Nukiwa, T. (2013) Deterioration in Regional Health Status after the Acute Phase of a Great Disaster: Respiratory Physicians' Experiences of the Great East Japan Earthquake. Respiratory Investigation, 51, 50-55. http://dx.doi.org/10.1016/j.resinv.2012.12.003

[24] Kobayashi, S., Hanagama, M., Yamanda, S., Satoh, H., Tokuda, S., Kobayashi, M., et al. (2013) Impact of a Large-Scale Natural Disaster on Patients with Chronic Obstructive Pulmonary Disease: The Aftermath of the 2011 Great East Japan Earthquake. Respiratory Investigation, 51, 17-23. http://dx.doi.org/10.1016/j.resinv.2012.10.004

[25] Yamanda, S., Hanagama, M., Kobayashi, S., Satou, H., Tokuda, S., Niu, K., et al. (2013) The Impact of the 2011 Great East Japan Earthquake on Hospitalisation for Respiratory Disease in a Rapidly Aging Society: A Retrospective Descriptive and Cross-Sectional Study at the Disaster Base Hospital in Ishinomaki. BMJ Open, 3, e000865. http://dx.doi.org/10.1136/bmjopen-2012-000865

[26] Fukuhara, A., Sato, S., Uematsu, M., Misa, K., Nikaido, T., Inokoshi, Y., et al. (2012) Impacts of the 3/11 Disaster in Fukushima on Asthma Control. American Journal of Respiratory and Critical Care Medicine, 186, 1309-1310. http://dx.doi.org/10.1164/ajrccm.186.12.1309

\section{Appendix}

The Fukushima Health Management Survey Group Chairpersons:

Masafumi Abe (Executive Director, Radiation Medical Center for the Fukushima Health Management Survey); Shunichi Yamashita, Kenji Kamiya, and Seiji Yasumura (Senior Directors, Radiation Medical Center for the Fukushima Health Management Survey); Makoto Akashi (National Institute of Radiological Sciences); Kazunori Kodama and Kotaro Ozasa (The Radiation Effects Research Foundation). 
Submit or recommend next manuscript to SCIRP and we will provide best service for you:

Accepting pre-submission inquiries through Email, Facebook, LinkedIn, Twitter, etc. A wide selection of journals (inclusive of 9 subjects, more than 200 journals)

Providing 24-hour high-quality service

User-friendly online submission system

Fair and swift peer-review system

Efficient typesetting and proofreading procedure

Display of the result of downloads and visits, as well as the number of cited articles

Maximum dissemination of your research work

Submit your manuscript at: http://papersubmission.scirp.org/

Or contact ojog@scirp.org 